\title{
ANALISIS PROTEKSI RELE JARAK PADA SALURAN TRANSMISI 150 KV GARUDA SAKTI - PASIR PUTIH MENGGUNAKAN PSCAD
}

\author{
Hari Asman ${ }^{1}$, Hamzah Eteruddin ${ }^{2}$, Arlenny ${ }^{3}$ \\ 1,2,3 Program Studi Teknik Elektro, Fakultas Teknik, Universitas Lancang Kuning Pekanbaru. \\ Jl. Yos Sudarso km. 8 Rumbai, Pekanbaru, Telp. (0761) 52324 \\ Email: idinforex@gmail.com, hamzah@unilak.ac.id, arlenny@unilak.ac.id
}

\begin{abstract}
ABSTRAK
Transmisi daya listrik menggunakan saluran udara tegangan tinggi, sehingga sangat rentan terhadap gangguan karena jarak yang sangat jauh. Oleh karena itu, dibutuhkan keandalan sistem proteksi yang tinggi untuk mengamankan saluran udara tersebut. Untuk memenuhi keandalan tersebut, maka pada saluran transmisi perlu dilakukan pemasangan rele jarak. Objek penelitian pada saluran transmisi yang menghubungkan Gardu Induk Garuda Sakti dan Gardu Induk Pasir Puth yang dikelola oleh PT. PLN (Persero) Unit Pelayanan Transmisi Pekanbaru. Saat penelitian ini dilakukan Penghantar 150 kV Garuda Sakti - Pasir Putih belum beroperasi. Dalam penelitian ini dilakukan perhitungan nilai impedansi primer dan impedansi sekunder penghantar 150 kV Garuda Sakti-Pasir Putih dengan panjang penghantar sejauh 31,16 km kemudian setting rele jarak pada zona-1, zona-2, dan zona-3, lalu disimulasikan dengan menggunakan software PSCAD. Berdasarkan analisa yang telah dilakukan diperoleh hasil perhitungan rele jarak di penghantar $150 \mathrm{kV}$ Garuda Sakti-Pasir Putih pada zona-1 sebesar 1,0529 Ohm, zona-2 sebesar 2,2519 Ohm, dan zona-3 sebesar 3,3778 $\mathrm{Ohm}$. Kemudian hasil perhitungan disimulasikan dengan menggunakan software PSCAD dan didapatkan semua gelombang impedansi gangguan berada dalam lingkaran zona yang menandakan rele jarak akan bekerja saat terjadi gangguan.
\end{abstract}

Kata kunci : Rele Jarak, Saluran Transmisi, Sistem Proteksi, Impedansi, PSCAD

\begin{abstract}
Power transmission uses high-voltage overhead line, making it extremely susceptible to disturbance because very long distances. Therefore, it needed protection system with high reliability to protect the overhead line transmission. To get the reliability, then on the transmission line needs to be installed distance relay. The object of research on the transmission line that connects the Garuda Sakti Substation and the Pasir Putih Substation that managed by PT. PLN (Persero) Unit Pelayanan Transmisi Pekanbaru. At the time of this study, Line $150 \mathrm{kV}$ Garuda Sakti - Pasir Putih was not operated. In this research, calculation of primary impedance and secondary impedance of Line150 kV Garuda Sakti - Pasir Putih with as far as $31.16 \mathrm{~km}$, then distance relay setting in zone 1, zone 2, and zone 3 , then simulated using PSCAD software. Based on the analysis that has been done obtained distance relay calculation results of Line $150 \mathrm{kV}$ Garuda Sakti - Pasir Putih in zone 1 of $1.0529 \mathrm{Ohm}$, zone 2 of 2,2519 Ohm, and zone 3 of 3,3778O hm. Then the calculation result is simulated using PSCAD software and got all impedance faults waves are in zone circle indicating the distance relay will work when disturbance occurs.
\end{abstract}

Keywords: Distance Relay, Transmission Line, Protection System, Impedance, PSCAD

\section{PENDAHULUAN}

Sistem transmisi memegang peranan yang sangat penting dalam proses penyaluran daya. Oleh karena itu, pengaman pada saluran transmisi perlu mendapat perhatian yang serius dalam perencanaannya. Sistem transmisi sendiri merupakan sistem dinamis kompleks yang parameter-parameter dan keadaan sistemnya berubah secara terus menerus.
Panjang saluran transmisi yang mengakibatkan banyak sekali kemungkinan gangguan yang akan diterima oleh saluran transmisi, diantaranya sambaran petir, senar layang-layang, pohon tumbang dan lain sebagainya. Untuk itu dibutuhkan sistem proteksi yang sangan andal untuk menjaga berlangsungnya pengiriman daya melalui saluran transmisi yang telah terpasang. 
Di dalam sistem proteksi pada jaringan transmisi terdapat komponen utama yang sangat penting yaitu rele. Rele proteksi berfungsi untuk mendeteksi kondisi abnormal dalam suatu sistem jaringan transmisi dengan mengukur besaran listrik yang berada dalam kondisi normal dan gangguan.

Rele jarak (distance relay) digunakan sebagai pengaman pada saluran transmisi karena kemampuannya dalam menghilangkan gangguan (fault clearance) dengan cepat dan penyetelannya yang relatif mudah [1]. Kordinasi rele jarak selama ini berdasarkan parameter saluran transmisi dengan kompensasi perkiraan besarnya gangguan yang dihitung secara offline. Akan tetapi, dengan keadaan sistem yang berubah-ubah yang mengakibatkan parameter saluran transmisi juga berubah serta adanya gangguan yang tidak bisa diperkirakan besarnya, maka setting rele yang ada bisa menjadi tidak selektif. Oleh karena itu, diperlukan koordinasi rele yang lebih baik yang dapat menyesuaikan dengan keadaan sistem tersebut.

Pada tanggal 05 Oktober 2016, PT. PLN (Persero) Penyaluran dan Pusat Pengatur Beban Sumatera, Unit Pelayanan Transmisi Pekanbaru mengoperasikan Gardu Induk (GI) Pasir Putih merupakan gardu induk baru yang saat ini tenaga listriknya disuplai dari Gardu Induk Tenayan Raya. Dalam perencanaannya, sistem kelistrikan Gardu Induk Pasir Putih akan dihubungkan dengan Gardu Induk Garuda Sakti untuk memperkuat keandalan sistem penyaluran tenaga listrik khususnya di subsistem Sumatera Bagian Tengah.

Untuk meningkatkan keandalan penyediaan energi listrik, kebutuhan proteksi yang memadai tidak dapat dihindarkan. Salah satu yang menjadi proteksi utama pada saluran transmisi tegangan tinggi adalah rele jarak.

\section{METODE PENELITIAN}

\subsection{Data Teknis}

Data teknis konduktor SUTT 150 kV Garuda Sakti - Pasir Putih terdapat pada tabel 1.

Tabel 1. Data Konduktor SUTT 150 kV Garuda Sakti - Pasir Putih

\begin{tabular}{|l|l|}
\hline \multicolumn{1}{|c|}{ Parameter } & \multicolumn{1}{|c|}{ Keterangan } \\
\hline Jenis Konduktor & ACSR - 240 / 40 \\
Jumlah Konduktor per Phasa & 2 (double bundle) \\
Jumlah Sirkit & 2 \\
Panjang & $31,16 \mathrm{~km}$ \\
Jarak / spacing & $40 \mathrm{~cm}$ \\
Luas Penampang & 241.7 / 39,49 mm2 \\
Diameter & $21.793 \mathrm{~mm}$ \\
Jumlah Pilin & $26 / 7$ \\
\hline
\end{tabular}

Sumber data :PLN P3B Sumatera, 2017
Data teknis kawat tanah seperti pada tabel 2.

Tabel 2. Data teknis kawat tanah

\begin{tabular}{|l|l|}
\hline \multicolumn{1}{|c|}{ Jenis } & \multicolumn{1}{|c|}{$\begin{array}{c}\text { Ground Steel Wire } \\
(\mathrm{GSW})\end{array}$} \\
\hline Luas Penampang & $55 \mathrm{~mm}^{2}$ \\
Diameter seluruh & $9,6 \mathrm{~mm}$ \\
Radius (r) & $0.0048 \mathrm{~m}$ \\
Jumlah pilin & $7 \mathrm{buah}$ \\
Resistivitas pada 200 C $(\rho)$ & $12 \times 10^{-6}$ Ohm.cm \\
\hline
\end{tabular}

Sumber data PLN P3B Sumatera, 2017

Data kawat penghantar saluran transmisi $150 \mathrm{kV}$ Garuda Sakti - Pasir Putih terdapat pada tabel 3.

Tabel 3. Data SUTT $150 \mathrm{kV}$

\begin{tabular}{|c|c|c|c|c|c|}
\hline \multirow[b]{2}{*}{ No } & \multirow{2}{*}{$\begin{array}{l}\text { Penghantar } \\
150 \mathrm{kV}\end{array}$} & \multicolumn{4}{|c|}{ Data Konduktor } \\
\hline & & Jenis & $\mathrm{mm}^{2}$ & $\begin{array}{c}\text { Kond. / } \\
\mathrm{Ph}\end{array}$ & $\begin{array}{c}\text { Panjang } \\
(\mathrm{km})\end{array}$ \\
\hline 1 & $\begin{array}{l}\text { Garuda Sakti - } \\
\text { Pasir Putih } 1\end{array}$ & ACSR & $2 \times 240$ & 2 & 31.16 \\
\hline 2 & $\begin{array}{l}\text { Garuda Sakti - } \\
\text { Pasir Putih } 2\end{array}$ & ACSR & $2 \times 240$ & 2 & 31.16 \\
\hline 3 & $\begin{array}{l}\text { Pasir Putih 1- } \\
\text { Pangk.Kerinci }\end{array}$ & ACSR & $2 \times 240$ & 2 & 37.26 \\
\hline 4 & $\begin{array}{l}\text { Pasir Putih 1- } \\
\text { Pangk.Kerinci }\end{array}$ & ACSR & $2 \times 240$ & 2 & 37.26 \\
\hline
\end{tabular}

Sumber data : PLNP3B Sumatera, 2017

Rasio CT dan PT yang terpasang pada GI Garuda Sakti dan GI Pasir Putih pada tabel 4.

\begin{tabular}{|l|c|c|c|c|c|}
\multicolumn{5}{c|}{ Tabel 4. Data rasio CT dan PT } \\
\hline $\begin{array}{l}\text { Lokasi } \\
\text { Gardu } \\
\text { Induk }\end{array}$ & Bay & \multicolumn{2}{|c|}{$\begin{array}{c}\text { Rasio CT } \\
\text { (Amper) }\end{array}$} & \multicolumn{2}{|c|}{$\begin{array}{c}\text { Rasio PT } \\
\text { (Volt) }\end{array}$} \\
\cline { 3 - 6 } & Primer & Sekunder & Primer & Sekunder \\
\hline $\begin{array}{l}\text { Garuda } \\
\text { Sakti }\end{array}$ & $\begin{array}{c}\text { Pasir } \\
\text { Putih 1 } \\
\text { Garuda }\end{array}$ & 1600 & 1 & $150 \mathrm{k} \sqrt{3}$ & $100 \sqrt{3}$ \\
$\begin{array}{l}\text { Pakir } \\
\text { Pakti }\end{array}$ & Putih 2 & 1600 & 1 & $150 \mathrm{k} \sqrt{3}$ & $100 \sqrt{3}$ \\
$\begin{array}{l}\text { Putih } \\
\text { Pasir }\end{array}$ & $\begin{array}{c}\text { Garuda } \\
\text { Putih }\end{array}$ & 1600 & 1 & $150 \mathrm{k} \sqrt{3}$ & $100 \sqrt{3}$ \\
Garuda & 1600 & 1 & $150 \mathrm{k} \sqrt{3}$ & $100 \sqrt{3}$ \\
\hline
\end{tabular}

Sumber data : PLN UPT Pekanbaru, 2017

Data transformator daya GI Pasir putih seperti pada tabel 5 .

Tabel 5. Data name plate trafo daya GI Pasir Putih

\begin{tabular}{|c|c|c|c|c|}
\hline \multicolumn{5}{|c|}{ Trafo Daya 30 MVA GI Pasir Putih } \\
\hline Daya & Tegangan & Imp. SC & Fasor & Frekuensi \\
\hline 30 MVA & $150 / 20 \mathrm{kV}$ & $12,515 \%$ & Yyn5 & $50 \mathrm{~Hz}$ \\
\hline
\end{tabular}

Sumber data : PLN UPT Pekanbaru, 2017

\subsection{Metode Pengumpulan Data}

1. Melakukan pengamatan langsung dan atau turut serta dalam melakukan pengambilan data, dokumentasi, pengujian-pengujian dan lain sebagainya ditempat melaksanakan penelitian. 
2. Melakukan wawancara dan diskusi dengan pihak perusahaan tempat dilaksanakannya penelitian maupun dari pihak lain.

3. Melakukan pengumpulan referensi dari buku, jurnal, dan tulisan ilmiah lainnya yang berhubungan dengan penelitian.

4. Melakukan pengambilan data dari tempat pelaksanaan penelitian seperti name plate peralatan, single line diagram, dan data setting.

\subsection{Tahapan/Langkah Penelitian}

Diagram alir tahapan pembahasan seperti pada gambar 1.

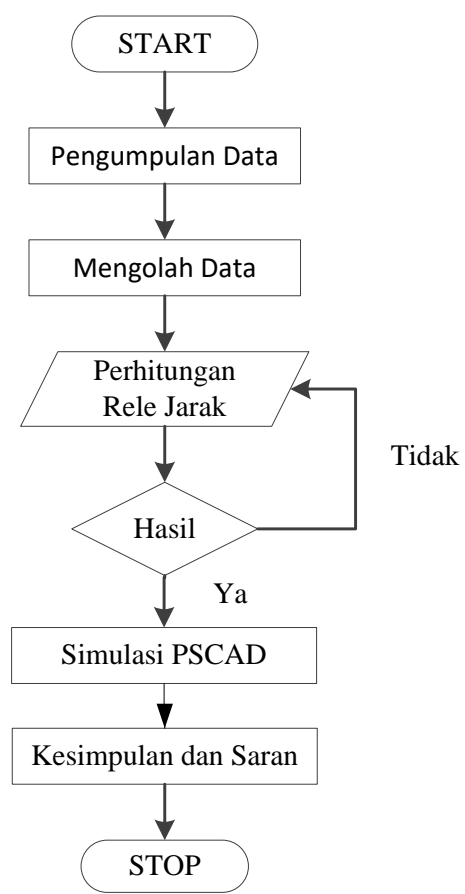

Gambar 1. Diagram alir tahapan pembahasan

1. Melakukan pengambilan data peralatan (CT, PT, CB) yang terpasang di GI Garuda Sakti dan GI Pasir Putih.

2. Melakukan pengambilan data penghantar pada saluran transmisi 150 kV Garuda Sakti - Pasir Putih di PT. PLN (Persero) Unit Induk Pembangunan II Sumbagteng.

3. Melakukan pengambilan data arus hubung singkat dan impedansi urutan gangguan pada GI Garuda Sakti dan GI Pasir Putih di PT. PLN (Persero) P3B Sumatera.

4. Melakukan perhitungan impedansi primer saluran.

5. Melakukan perhitungan nilai CT dan PT di sisi GI Garuda Sakti dan GI Pasir Putih.

6. Menghitung impedansi sekunder saluran.

7. Melakukan perhitungan rele jarak di GI Garuda Sakti dan GI Pasir Putih berikut Zona-Zonanya.
8. Melakukan validasi data dengan menggunakan software PSCAD.

\section{HASIL DAN PEMBAHASAN}

\subsection{Nilai Tahanan Konduktor}

Resistivitas bahan konduktor terdapat pada tabel 6 .

Tabel 6. Resistivitas $(\rho)$ bahan konduktor standar [1].

\begin{tabular}{|l|c|c|c|c|c|c|c|}
\hline \multirow{2}{*}{$\begin{array}{c}\text { Material } \\
(\%)\end{array}$} & \multicolumn{7}{|c|}{ Mikro - Ohm - cm } \\
\cline { 2 - 8 } & $\rho_{0}$ & $\rho_{20}$ & $\rho_{25}$ & $\rho_{50}$ & $\rho_{75}$ & $\rho_{80}$ & $\rho_{100}$ \\
\hline CU 100 & 1.58 & 1.72 & 1.75 & 1.92 & 2.09 & 2.12 & 2.26 \\
CU 95 & 1.63 & 2.77 & 1.80 & 1.97 & 2.14 & 2.18 & 2.31 \\
Al 61 & 2.60 & 2.83 & 2.89 & 3.17 & 3.46 & 3.51 & 3.74 \\
\hline
\end{tabular}

Faktor GMR terhadap lapisan dan jumlah pilin pada kawat tanah terdapat pada tabel 7.

Tabel 7. Faktor GMR (k) kawat tanah[1]

\begin{tabular}{|c|c|c|c|}
\hline \multicolumn{2}{|c|}{$\mathrm{Cu} / \mathrm{Al}$} & \multicolumn{2}{c|}{ ACSR } \\
\hline $\begin{array}{c}\text { Jumlah Pilin } \\
\text { (Strands) }\end{array}$ & $\begin{array}{c}\text { Faktor GMR } \\
(k)\end{array}$ & $\begin{array}{c}\text { Jumlah } \\
\text { Pilin } \\
(\text { Strands })\end{array}$ & $\begin{array}{c}\text { Faktor } \\
\text { GMR } \\
(k)\end{array}$ \\
\hline 1 (solid) & 0.7788 & 26 & 0.809 \\
7 & 0.7256 & 30 & 0.829 \\
19 & 0.7577 & 54 & 0.81 \\
37 & 0.7678 & - & - \\
61 & 0.7722 & - & - \\
91 & 0.7740 & - & - \\
127 & 0.7760 & - & - \\
169 & 0.7760 & - & - \\
\hline \multicolumn{2}{|r}{}
\end{tabular}

Konduktivitas dan resistivitas konduktor pada suhu $20^{\circ} \mathrm{C}$ serta temperatur konstan konduktor terdapat pada tabel 8.

Tabel 8. Konduktivitas, resistivitas pada suhu $20^{\circ} \mathrm{C}$ dan temperatur konstan konduktor [1].

\begin{tabular}{|c|c|c|c|c|}
\hline \multirow[b]{2}{*}{ Material } & \multirow{2}{*}{$\begin{array}{c}\text { Konduktivi } \\
\text { tas } \\
(\%)\end{array}$} & \multicolumn{2}{|c|}{ Resistivitas Saat $20^{\circ} \mathrm{C}$} & \multirow{2}{*}{$\begin{array}{c}\text { Temp. } \\
\text { Konstan } \\
\left({ }^{\circ} \mathrm{C}\right)\end{array}$} \\
\hline & & $\begin{array}{l}\Omega m \\
\times 10^{-8}\end{array}$ & $\Omega-c m / f t$ & \\
\hline $\begin{array}{l}\text { Copper : } \\
\text { Annealed } \\
\text { Hard- } \\
\text { drawn } \\
\end{array}$ & $\begin{array}{l}100 \\
97,3\end{array}$ & $\begin{array}{l}1,72 \\
1,77\end{array}$ & $\begin{array}{l}10,37 \\
10,66\end{array}$ & $\begin{array}{l}234,5 \\
241,5\end{array}$ \\
\hline $\begin{array}{l}\text { Aluminium } \\
: \\
\text { Hard- } \\
\text { drawn }\end{array}$ & 61 & 2,83 & 17,00 & 228,1 \\
\hline Brass & $20-27$ & $6,4-8,4$ & $38-51$ & 480 \\
\hline Iron & 17,2 & 10 & 60 & 180 \\
\hline Silver & 108 & 1,59 & 9,6 & 243 \\
\hline Sodium & 40 & 4,3 & 26 & 207 \\
\hline Steel & $2-14$ & $12-88$ & $72-530$ & $\begin{array}{c}180- \\
980\end{array}$ \\
\hline
\end{tabular}


Koefisien temperatur bahan konduktor terdapat pada tabel 9.

Tabel 9. Koefisien temperatur $(\alpha)$ bahan konduktor standar [1]

\begin{tabular}{|c|c|c|c|c|c|c|c|}
\hline \multirow{2}{*}{$\begin{array}{c}\text { Material } \\
(\%)\end{array}$} & \multicolumn{6}{|c|}{ Koefisien Temperatur dari Tahanan $\times 10^{-3}$} \\
\cline { 2 - 8 } & $\alpha_{0}$ & $\alpha_{20}$ & $\alpha_{25}$ & $\alpha_{50}$ & $\alpha_{75}$ & $\alpha_{80}$ & $\alpha_{100}$ \\
\hline CU 100 & 4.27 & 3.93 & 3.83 & 3.52 & 3.25 & 3.18 & 2.99 \\
\hline CU 95 & 4.15 & 3.83 & 3.76 & 3.44 & 3.16 & 3.12 & 2.93 \\
\hline Al 61 & 4.38 & 4.03 & 3.95 & 3.60 & 3.30 & 3.25 & 3.05 \\
\hline
\end{tabular}

Tahanan konduktor dapat ditentukan dengan persamaan 1 [1].

$R=\rho \frac{l}{A}$

Nilai tahanan DC konduktor yang tidak berbeban setiap kilometer adalah :

$R_{20-D C}=0,0585 \mathrm{ohm} / \mathrm{km}$

Untuk konduktor pilin (stranded conductor) lebih dari 2 lapis tahanan AC konduktor dikalikan dengan faktor 1,02 [1].

$$
\begin{aligned}
R_{20-A C} & =1,02 \times 0,0585 \\
& =0,0597 \mathrm{ohm} / \mathrm{km}
\end{aligned}
$$

Berdasarkan tabel 9 harga $\alpha_{20}=4,03 \times 10^{-3}$, sehingga terperatur konstan konduktor $\left(T_{0}\right)$ adalah [1] :

$$
\begin{aligned}
T_{0} & =\left(\frac{1}{\alpha_{t 1}}\right)-T_{1}=\left(\frac{1}{0,00403}\right)-20 \\
& =228,1390^{\circ} \mathrm{C}
\end{aligned}
$$

Tahanan AC konduktor $\left(R_{50-A C}\right)$ saat beban penuh (suhu $50^{\circ} \mathrm{C}$ ) dapat dihitung dengan persamaan [1].

$$
\begin{aligned}
R_{50-A C} & =R_{20}\left[\frac{T_{0}+T_{2}}{T_{0}+T_{1}}\right] \\
& =0.0669 \mathrm{ohm} / \mathrm{km}
\end{aligned}
$$

\subsection{Tahanan Kawat Tanah}

Untuk tahanan DC pada suhu $20^{\circ} \mathrm{C}$ konduktor kawat tanah/GSW (Ground Steel Wire) $55 \mathrm{~mm}^{2}$ adalah [1] :

$$
\begin{aligned}
R_{20} & =12 \times 10^{-11} \frac{1}{55 \times 10^{-12}} \\
& =2,1818 \mathrm{ohm} / \mathrm{km}
\end{aligned}
$$

Berdasarkan tabel 5, harga $T_{0}$ untuk bahan steel adalah $180^{\circ} \mathrm{C}$ maka tahanan kawat tanah saat suhu $50^{\circ} \mathrm{C}$ adalah :

$R_{g}=2,5091 \mathrm{ohm} / \mathrm{km}$

\subsection{Induktansi, Reaktansi, dan Impedansi Konduktor}

Untuk menghitung induktansi konduktor $(L)$ terlebih dahulu harus dihitung jarak rata-rata geometri (GMD) dan jari-jari rata-rata geometri konduktor (GMR).

Jari - jari konduktor (r) adalah [1]:

$r=\frac{d}{2}=\frac{21,793}{2}=0,0109$ meter

Berdasarkan tabel 7 untuk faktor GMR $(k)$ dengan jumlah pilin ACSR 26 buah adalah 0,809 sehingga jari-jari imaginer konduktor $\left(r^{\prime}\right)$ dapat ditentukan dengan persamaan 2 [1].

$r^{\prime}=k \times r$

$r^{\prime}=0,0088$ meter

Jarak antar kawat konduktor SUTT 150 kV seperti pada tabel 10 .

Tabel 10. Jarak antar kawat konduktor saluran transmisi 3 phasa $150 \mathrm{kV}$

\begin{tabular}{|ccc|c|}
\hline \multicolumn{2}{|c|}{ Jarak Antar Kawat } & Panjang (m) \\
\hline 1 & - & 2 & 4,3 \\
\hline 1 & - & 3 & 8,6 \\
\hline 1 & - & 4 & 11,610 \\
\hline 1 & - & 5 & 8,906 \\
\hline 1 & - & 6 & 7,8 \\
\hline 2 & - & 3 & 4,3 \\
\hline 2 & - & 4 & 8,906 \\
\hline 2 & - & 5 & 7,8 \\
\hline 2 & - & 6 & 8,906 \\
\hline 3 & - & 4 & 7,8 \\
\hline 3 & - & 5 & 8,906 \\
\hline 3 & - & 6 & 11,610 \\
\hline 4 & - & 5 & 4,3 \\
\hline 4 & - & 6 & 7,8 \\
\hline 5 & - & 6 & 4,3 \\
\hline a & - & G & 4,119 \\
\hline b & - & G & 8,4095 \\
\hline c & - & G & 12,706 \\
\hline
\end{tabular}
adalah :

Berdasarkan tabel 10 jarak antar konduktor

$d_{12}=d_{23}=d_{45}=d_{56}=4,3$ meter

$d_{13}=d_{46}=8,6$ meter 
$d_{15}=d_{24}=d_{26}=d_{35}=8,906$ meter

$d_{16}=d_{34}=d_{25}=7,8$ meter

$d_{14}=d_{36}=11,61$ meter

Jarak rata-rata geometris konduktor $\left(D_{e q}\right)$ atau biasa disebut GMD dapat ditentukan dengan persamaan 3 [2].

$G M D=\sqrt[n]{d_{12} \times d_{13} \times d_{23} \times \ldots \times d_{m n}}$

Jarak rata-rata geometris konduktor $\left(D_{e q}\right)$ adalah :

$D_{e q}=G M D=6,794370484$ meter

$D_{s}=\sqrt[6]{\left(r^{\prime}\right)^{3} d_{14} d_{25} d_{36}}$ meter

$$
=0,2994 \text { meter }
$$

Jari-jari rata-rata geometris konduktor $\left(D_{S L}\right)$ untuk penghantar 2 sirkit 3 phasa dapat dihitung dengan persamaan 4 [2].

$$
\begin{aligned}
D_{S L} & =G M R=\sqrt[2]{D_{s} \times d} \\
& =\sqrt[2]{0,2994 \times 0,4} \\
& =0,3461 \text { meter }
\end{aligned}
$$

Induktansi konduktor dapat dihitung dengan menggunakan persamaan 5 [3].

$$
\begin{aligned}
L & =2 \times 10^{-7} \ln \frac{D_{e q}}{D_{S L}}(5) \\
& =5,9545 \times 10^{-7} \mathrm{H} / \text { meter } \\
& =0,00096 \mathrm{H} / \mathrm{mil}
\end{aligned}
$$

Frekuensi yang digunakan oleh sistem tenaga listrik adalah $50 \mathrm{~Hz}$, sehingga reaktansi induktif konduktor $\left(X_{L}\right)$ dapat ditentukan dengan persamaan 6 [2].

$$
\begin{aligned}
X_{L} & =2 \pi f L \Omega / \text { mile } \\
& =0,3011 \mathrm{ohm} / \mathrm{mil} \\
& =0,1871 \mathrm{Ohm} / \mathrm{km}
\end{aligned}
$$

Impedansi konduktor (Z) adalah [4] :

$$
\begin{aligned}
Z & =R+j X_{L} \\
& =0,0669+j 0,1871 \mathrm{Ohm} / \mathrm{km} \\
& =0,1987 \angle 70.3178^{\circ} \mathrm{Ohm} / \mathrm{km}
\end{aligned}
$$


urutan nol konduktor phasa $\left(Z_{0(a)}\right)$, impedansi urutan nol tanah $\left(Z_{0(g)}\right)$, reaktansi kawat phasa ke ground $\left(X_{a g}, X_{b g}, X_{c g}\right)$, reaktansi rata-rata kawat phasa ke ground $\left(X_{d g}\right)$, dan impedansi urutan nol konduktor ke ground $\left(Z_{0(a g)}\right)$.

Tahanan rata-rata pentanahan $\left(R_{e}\right)$ dapat ditentukan dengan persamaan 8 [2].

$$
\begin{aligned}
R_{e} & =0.00477 \times f \\
& =0,2385 \mathrm{Ohm} / \mathrm{mil} \\
& =0,1482 \mathrm{Ohm} / \mathrm{km}
\end{aligned}
$$

Nilai parameter jarak $\left(D_{e}\right)$ bergantung pada resistivitas bumi $(\rho)$ dan frekuensi saluran seperti pada Tabel 11.

Tabel 11 Parameter Jarak Sesuai Jenis Tanah [2]

\begin{tabular}{|l|c|c|c|}
\hline \multirow{2}{*}{$\begin{array}{l}\text { Return Earth } \\
\text { Condition }\end{array}$} & \multirow{2}{*}{$\begin{array}{c}\text { Resistivity } \\
(\rho)\end{array}$} & \multicolumn{2}{|c|}{ Parameter Jarak $\left(D_{e}\right)$} \\
\cline { 3 - 4 } & $\Omega \mathrm{m}$ & Freq $=50$ & Freq $=60$ \\
$\mathrm{~Hz}$ & $\mathrm{~Hz}$ \\
\hline $\begin{array}{l}\text { Sea water } \\
\text { Swampy }\end{array}$ & $0,01-1,0$ & $9,3-93,05$ & $27.9-279$ \\
ground & $10-100$ & $294-930,5$ & $882-2.790$ \\
$\begin{array}{l}\text { Average } \\
\text { damp earth }\end{array}$ & 100 & 931 & 2.790 \\
$\begin{array}{l}\text { Dry earth } \\
\text { Pure slate }\end{array}$ & 1.000 & 2.943 & 8.820 \\
Sandstone & $10^{7}$ & 294.300 & 882.000 \\
& $10^{9}$ & 2.943 .000 & 8.820 .000 \\
\hline
\end{tabular}

Berdasarkan tabel 11 parameter jarak $\left(D_{e}\right)$ untuk frekuensi $50 \mathrm{~Hz}$ adalah sebesar $931 \mathrm{ft}$, sehingga reaktansi rata-rata pentanahan $\left(X_{e}\right)$ dapat ditentukan dengan persamaan 9 [2].

$X_{e}=3 \times \omega k \times \ln D_{e}$

$$
\begin{aligned}
& =2,0736 \mathrm{Ohm} / \mathrm{mill} \\
& =1,2885 \mathrm{Ohm} / \mathrm{km}
\end{aligned}
$$

Konstanta induktansi seperti pada tabel 12.

Tabel 12. Konstanta induktansi [2]

\begin{tabular}{|c|c|c|c|}
\hline Constant & $\begin{array}{c}\text { Unit of } \\
\text { Length }\end{array}$ & $\begin{array}{c}\text { Natural } \\
\text { Logarithm } \\
(\text { ln })\end{array}$ & $\begin{array}{c}\text { Base 10 } \\
\text { Logarithm } \\
\left(\log _{10}\right)\end{array}$ \\
\hline$K$ & $\mathrm{~km}$ & $0,2000 \times 10^{-3}$ & $0,4605 \times 10^{-3}$ \\
$2 \pi k$ & $\mathrm{mi}$ & $0,3219 \times 10^{-3}$ & $0,7411 \times 10^{-3}$ \\
& $\mathrm{~km}$ & $1,257 \times 10^{-3}$ & $2,893 \times 10^{-3}$ \\
$f=50 \mathrm{~Hz}$ & $\mathrm{mi}$ & $2,022 \times 10^{-3}$ & $4,656 \times 10^{-3}$ \\
$f k$ & $\mathrm{~km}$ & 0,01000 & 0,02302 \\
$\omega k$ & $\mathrm{mi}$ & 0,01609 & 0,03705 \\
& $\mathrm{~km}$ & 0,06283 & 0,1446 \\
$f=60 \mathrm{~Hz}$ & $\mathrm{mi}$ & 0,10111 & 0,2328 \\
$f k$ & $\mathrm{~km}$ & 0,01200 & 0,02763 \\
$\omega k$ & $\mathrm{mi}$ & 0,01931 & 0,04446 \\
& $\mathrm{~km}$ & 0,07539 & 0,1736 \\
& $\mathrm{mi}$ & 0,12134 & 0,2794 \\
\hline
\end{tabular}

mpedansi urutan nol konduktor ke ground $\left(Z_{0(a g)}\right)$ dapat dihitung dengan persamaan 12 [2].

$Z_{0(a g)}=R_{e}+j\left(X_{e}-3 X_{d g}\right)$

$=0,1482+j 1,28090 \mathrm{hm} / \mathrm{km}$

Nilai impedansi urutan nol $\left(Z_{0}\right)$ ditentukan dengan persamaan 15 [2].

$$
\begin{aligned}
Z_{0} & =Z_{0(a)}-\frac{Z_{0(a g)}{ }^{2}}{Z_{0(g)}} \\
& =0,4005+j 1,37180 \mathrm{hm} / \mathrm{km} \\
& =1,4291 \angle 73.72590 \mathrm{hm} / \mathrm{km}
\end{aligned}
$$

dihitung dengan persamaan 12[2]

$$
Z_{0(g)}=3 R_{g}+R_{e}+j\left(X_{e}+3 X_{g}\right)
$$
$2,893 \times 10^{-3}$, sehingga reaktansi kawat phasa ke ground $\left(X_{a g}, X_{b g}, X_{c g}\right)$ dapat dihitung dengan persamaan 13 [2].

$\left(X_{d g}\right)$ dapat dihitung dengan persamaan 14 [2].

$$
=0,0025 \mathrm{Ohm} / \mathrm{km}
$$


Berdasarkan tabel 12 reaktansi antar kawat phasa adalah [2]:

$$
\begin{aligned}
X_{d 16} & =2 \pi k \times \log _{10} d_{16} \\
& =2,893 \times 10^{-3} \times \log _{10} 7,8 \\
& =0,0026 \mathrm{Ohm} / \mathrm{km} \\
X_{d 25} & =2,893 \times 10^{-3} \times \log _{10} 7,8 \\
& =0,0026 \mathrm{Ohm} / \mathrm{km} \\
X_{d 34} & =2,893 \times 10^{-3} \times \log _{10} 7,8 \\
& =0,0026 \mathrm{Ohm} / \mathrm{km} \\
X_{d 15} & =2,893 \times 10^{-3} \times \log _{10} 8,906 \\
& =0,0027 \mathrm{Ohm} / \mathrm{km} \\
X_{d 14} & =2,893 \times 10^{-3} \times \log _{10} 11,610 \\
& =0,0031 \mathrm{Ohm} / \mathrm{km} \\
X_{d 24} & =2,893 \times 10^{-3} \times \log _{10} 8,906 \\
& =0,0027 \mathrm{Ohm} / \mathrm{km}
\end{aligned}
$$

Reaktansi rata-rata antar konduktor phasa $\left(X_{d 3}\right)$ ditentukan dengan persamaan 16 [2].

$$
\begin{aligned}
X_{d 3} & =\frac{X_{d 16}+X_{d 25}+X_{d 34}+2\left(X_{d 15}+X_{d 14}+X_{d 24}\right)}{3}(16) \\
& =0,00830 \mathrm{hm} / \mathrm{km}
\end{aligned}
$$

Impedansi gandeng urutan nol konduktor $\left(Z_{0 m(a)}\right)$ ditentukan dengan persamaan 17 [2].

$$
\begin{aligned}
Z_{0 m(a)} & =R_{e}+j\left(X_{e}+X-3 X_{d 3}\right) \\
& =0,1482+j 1,45040 \mathrm{Ohm} / \mathrm{km} \\
& =1,4579 \angle 84,16470 \mathrm{om} / \mathrm{km}
\end{aligned}
$$

Nilai impedansi gandengan urutan nol $\left(Z_{0 m}\right)$ ditentukan dengan persamaan 18 [2].

$$
\begin{aligned}
Z_{0 m} & =Z_{0 m(a)}-\frac{Z_{0(a g)}{ }^{2}}{Z_{0(g)}} \\
& =0,3335+1,35250 \mathrm{hm} / \mathrm{km} \\
& =1,3930 \angle 76,1467^{\circ} \mathrm{Ohm} / \mathrm{km}
\end{aligned}
$$

\subsection{Zona Pengamanan Rele Jarak}

Berdasarkan tabel 3 panjang SUTT $150 \mathrm{kV}$ Garuda Sakti-Pasir Putih adalah 31,16 km. Sehingga impedansi saluran $\left(Z_{L 1}\right)$ dihitung menggunakan persamaan 19 [5].

$$
\begin{aligned}
Z_{L 1} & =Z \times l_{1} \\
& =(0.0669+j 0,1871) 31,16 \\
& =2,0857+j 5,8307 \text { Ohm }
\end{aligned}
$$

Sedangkan impedansi SUTT 150 kV Pasir Putih - Pangkalan $\operatorname{Kerinci}\left(Z_{L 2}\right)$ adalah [5] :

$$
\begin{aligned}
Z_{L 2} & =Z \times l_{2} \\
& =(0.0669+j 0,1871) 37,26 \\
& =2,4940+j 6,9722 \text { ohm }
\end{aligned}
$$

Ratio trafo tengangan (nPT) adalah [5] :

$$
n P T=\frac{E_{\text {Primer }}}{E_{\text {Sekunder }}}=\frac{1500000 \sqrt{3}}{100 \sqrt{3}}=15000
$$

Ratio trafo arus (nCT) adalah (Coock, 1985):

$n C T=\frac{I_{\text {Primer }}}{I_{\text {Sekunder }}}=\frac{1600}{1}=1600$

Impedansi sekunder $\left(Z_{S}\right)$ dapat dihitung menggunakan persamaan 21, sehingga impedansi sekunder SUTT 150 kV Garuda Sakti - Pasir Putih $\left(Z_{S 1}\right)$ adalah [5] :

$$
\begin{aligned}
Z_{S 1} & =\frac{n C T}{n P T} \times Z_{l} \\
& =\frac{1600}{15000} \times(2,0857+j 5,8307) \\
& =0,2225+j 1,29720 \mathrm{hm} \\
& =1,3161 \angle 80,26820 \mathrm{hm}
\end{aligned}
$$

Impedansi sekunder SUTT 150 kV Pasir Putih Pangkalan Kerinci $\left(Z_{S 2}\right)$ adalah :

$$
\begin{aligned}
Z_{S 2} & =\frac{1600}{15000} \times(2,4934+j 6,9722) \\
& =0,2660+j 1,8548 \mathrm{Ohm} \\
& =1,8737 \angle 81,8379^{\circ} \mathrm{Ohm}
\end{aligned}
$$

\subsubsection{Setting Zona 1}

Perhitungan setting Zona 1 ditentukan dengan persamaan 22 [6].

$Z_{\text {zone } 1}=0,8 \times Z_{S 1}$ 


$$
\begin{aligned}
& =0,1778+j 1,0377 \mathrm{Ohm} \\
& =1,0529 \angle 80,2778^{\circ} \mathrm{Ohm}
\end{aligned}
$$

Setting waktu Zona $1\left(t_{\text {zone } 1}\right)$ dibuat sesaat :

$t_{\text {zone } 1}=0$ detik

\subsubsection{Setting Zona 2}

Berdasarkan tabel 5, impedansi trafo $\left(Z_{T}\right)$ adalah [6] :

$$
\begin{aligned}
& Z_{T R}= \frac{k V^{2}}{M V A} \times \% Z_{T} \\
&=93,86250 \mathrm{hm}
\end{aligned}
$$

Impedansi setting Zona 2 minimum ditentukan dengan menggunakan persamaan 23 [6].

$$
\begin{aligned}
\text { Zona } 2 \mathrm{~min} & =1,2 \times Z_{S 1} \\
& =0,2670+j 1,5566 \mathrm{Ohm} \\
& =1,5793 \angle 80,2682^{\circ} \mathrm{Ohm}
\end{aligned}
$$

Impedansi setting Zona 2 maksimum penghantar ditentukan dengan menggunakan persamaan 24 [6].

$$
\begin{aligned}
Z_{\text {ona } 2 \max _{1}} & =0,8\left(Z_{S 1}+0,8 \times Z_{S 2}\right) \\
& =0,3482+j 2,22480 h m \\
& =2,2519 \angle 81,1040^{\circ} \mathrm{Ohm}
\end{aligned}
$$

Impedansi setting Zona 2 maksimum penghantar dan transformator ditentukan dengan menggunakan persamaan 25 [6].

$$
\begin{aligned}
{\text { Zona } 2 \max _{2}} & =0,8\left(Z_{S 1}+K \times Z_{T R}\right) \\
& =0,1780+j 38,5827 \mathrm{Ohm} \\
& =38,5831 \angle 89,7357^{\circ} \mathrm{Ohm}
\end{aligned}
$$

Setting impedansi Zona 2 yang dipakai adalah nilai yang terbesar antara Zona 2 minimum (Zona 2 min) dan Zona 2 maksimum (Zona $2 \max _{1}$ ), sehingga setting impedansi Zona 2 $\left(Z_{\text {zone } 2}\right)$ adalah :

$$
\begin{aligned}
Z_{\text {zone } 2} & =0,3482+j 2,2248 \mathrm{Ohm} \\
& =2,2519 \angle 81,1040^{\circ} \mathrm{Ohm}
\end{aligned}
$$

Untuk setting waktu Zona $2\left(t_{\text {zone2 }}\right)$ adalah : $t_{\text {zone } 2}=0,4$ detik

\subsubsection{Setting Zona 3}

Impedansi setting Zona 3 minimum ditentukan dengan menggunakan persamaan 26 [6].

$$
\begin{aligned}
\text { Zona } 3 \mathrm{~min} & =1,2\left(Z_{S 1}+0,8 \times Z_{S 2}\right) \\
& =0,5223+j 3,3372 \mathrm{Ohm} \\
& =3,3778 \angle 81.1040^{\circ} \mathrm{Ohm}
\end{aligned}
$$

Impedansi setting Zona 2 maksimum penghantar ditentukan dengan menggunakan persamaan 27 [6].

$$
\begin{aligned}
\operatorname{Zona}_{3 \max _{1}} & =0,8\left(Z_{S 1}+1,2 \times Z_{S 2}\right) \\
& =0,4334+j 2.8183 \mathrm{Ohm} \\
& =2,8514 \angle 81,2583^{\circ} \mathrm{Ohm}
\end{aligned}
$$

Impedansi setting Zona 3 maksimum penghantar dan transformator ditentukan dengan menggunakan persamaan 28 [6].

$$
\begin{aligned}
{\text { Zona } 3 \max _{2}} & =0,8\left(Z_{S 1}+K \times Z_{T R}\right) \\
& =0,1780+j 61,1097 \mathrm{Ohm} \\
& =61,1100 \angle 89,8331^{\circ} \mathrm{Ohm}
\end{aligned}
$$

Setting impedansi Zona 3 yang dipakai adalah nilai yang terbesar antara Zona 3 minimum (Zona $3 \mathrm{~min}$ ) dan Zona 3 maksimum (Zona $3 \max _{1}$ ), sehingga setting impedansi Zona 3 $\left(Z_{\text {zone } 3}\right)$ adalah :

$$
\begin{aligned}
Z_{\text {zone } 3}= & 0,5223+j 3,3372 \mathrm{Ohm} \\
& =3,3778 \angle 81,1040^{\circ} \mathrm{Ohm}
\end{aligned}
$$

Untuk setting waktu Zona $3\left(t_{\text {zone } 3}\right)$ adalah :

$t_{\text {zone } 3}=1,2$ detik

Faktor kompensasi urutan nol $\left(K_{0}\right)$ rele jarak untuk gangguan tanah adalah [2]:

$$
\begin{aligned}
K_{0} & =\frac{Z_{0}-Z}{3 Z} \\
& =2,0644 \angle 3,9582^{\circ}
\end{aligned}
$$

\subsection{Simulasi dengan PSCAD}

\subsubsection{Simulasi Zona 1}

Gangguan phasa-netral disimulasikan pada phasa R. Gangguan terjadi pada Zona 1, selama 1 cycle (0,02 detik) seperti pada gambar 2 . 

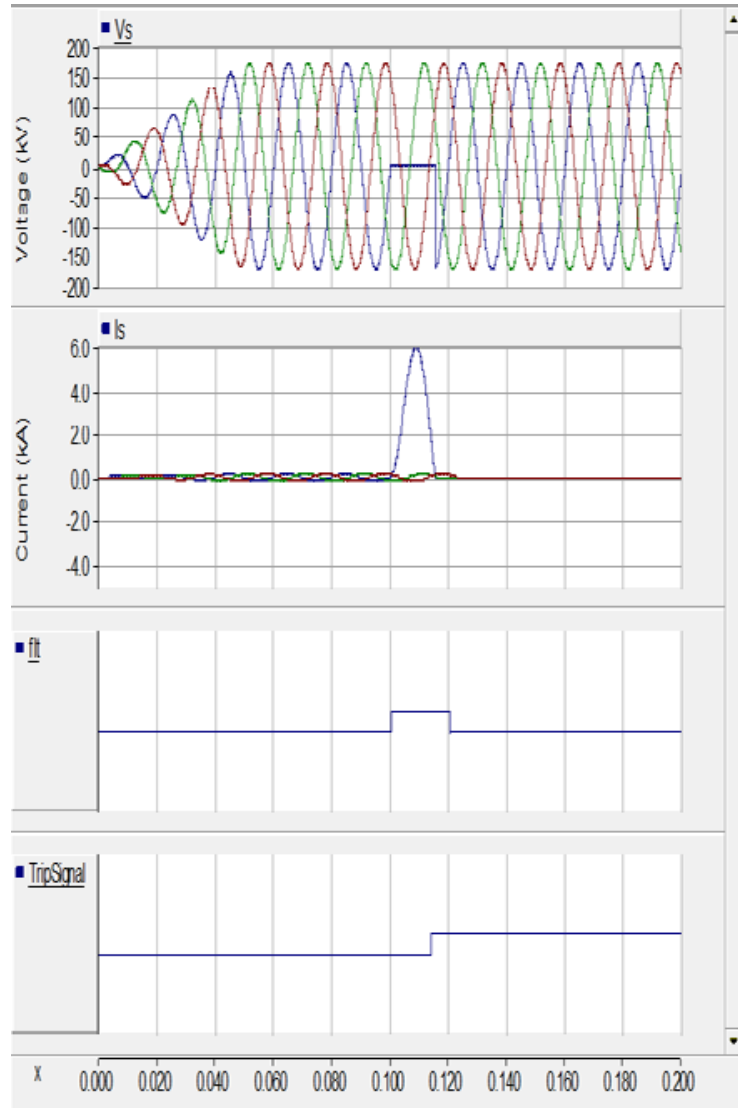

Gambar 2.Gelombang gangguan phasa-netral

Pada rele jarak, gelombang impedansi gangguan akan berada dalam lingkaran kurva mho Zona 1, sehingga rele akan bekerja dalam waktu seketika seperti pada gambar 3 .

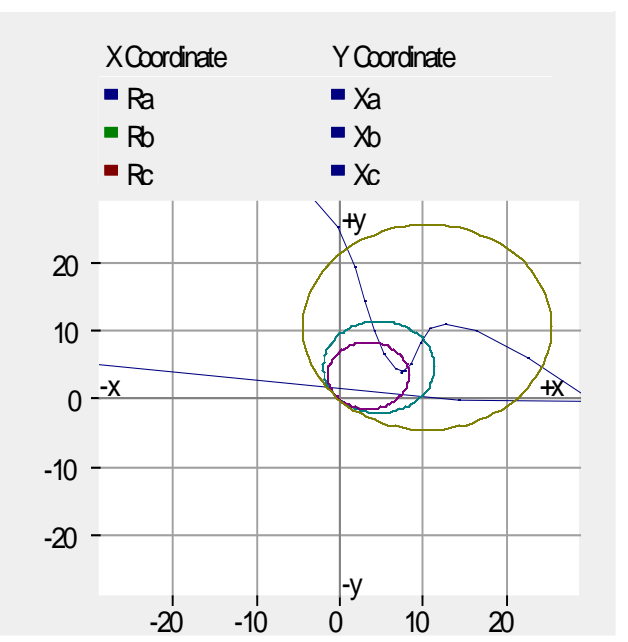

Gambar 3. Gelombang impedansi gangguan phasa-netral Zona 1

\subsubsection{Simulasi Zona 2}

Gangguan phasa-netral dibuat pada phasa R. Gangguan terjadi pada Zona 2, selama 0,4 detik seperti pada gambar 4.
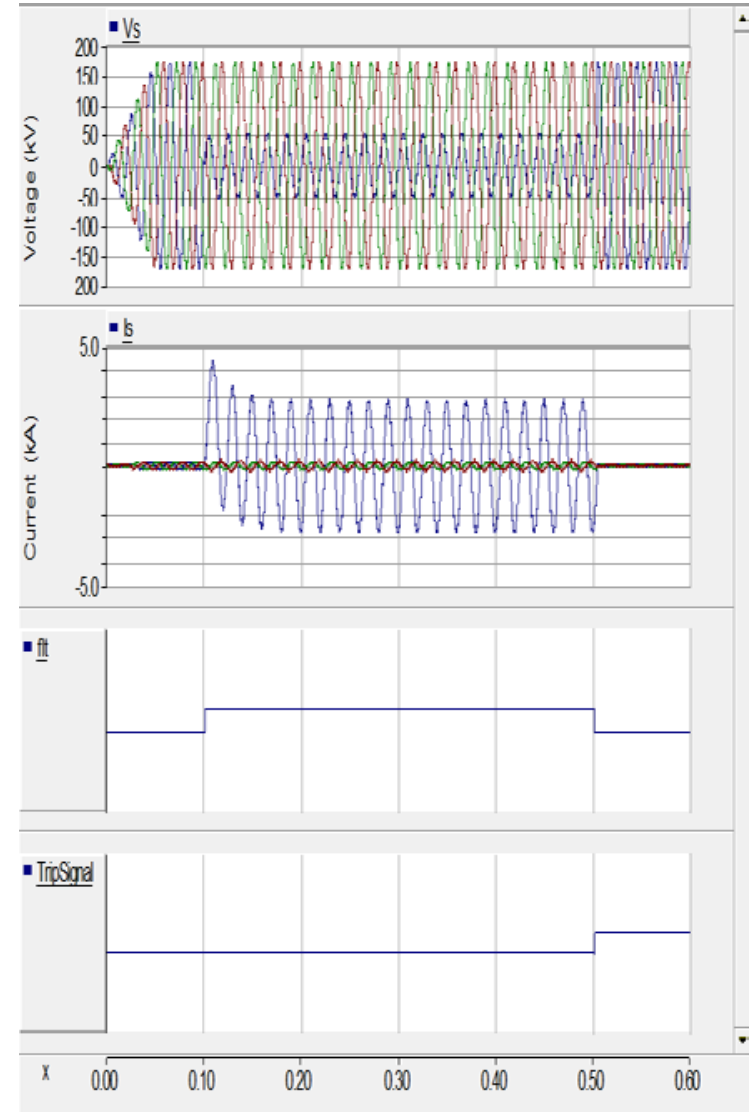

Gambar 4. Gelombang gangguan phasa-netral Zona 2

Pada rele jarak, gelombang impedansi gangguan akan berada dalam lingkaran kurva mho Zona 2, sehingga rele akan bekerja dalam waktu 0,4 detik seperti pada gambar 5 .

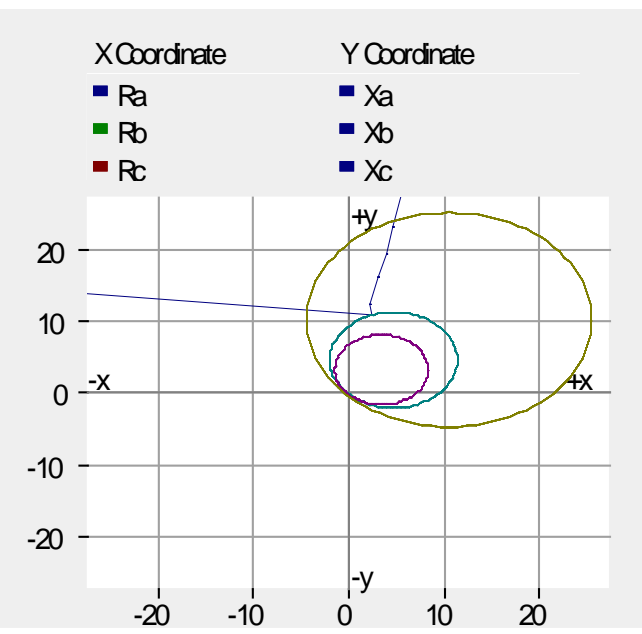

Gambar 5. Gelombang impedansi gangguan phasa- netral Zona 2

\subsubsection{Simulasi Zona 3}

Gangguan phasa-netral dibuat pada phasa R. Gangguan terjadi pada Zona 3, selama 1,2 detik seperti pada gambar 6 . 


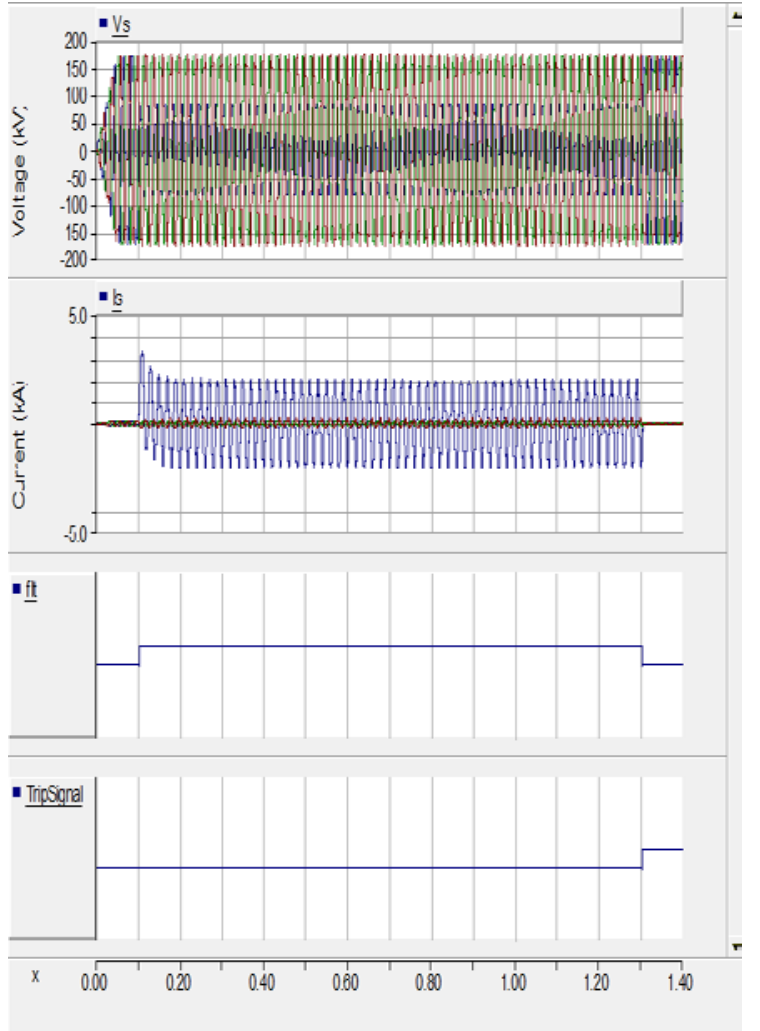

Gambar 6. Gelombang gangguan phasa-netral Zona 3

Pada rele jarak, gelombang impedansi gangguan akan berada dalam lingkaran kurva mho Zona 3, sehingga rele akan bekerja dalam waktu 1,2 detik seperti pada gambar 7.

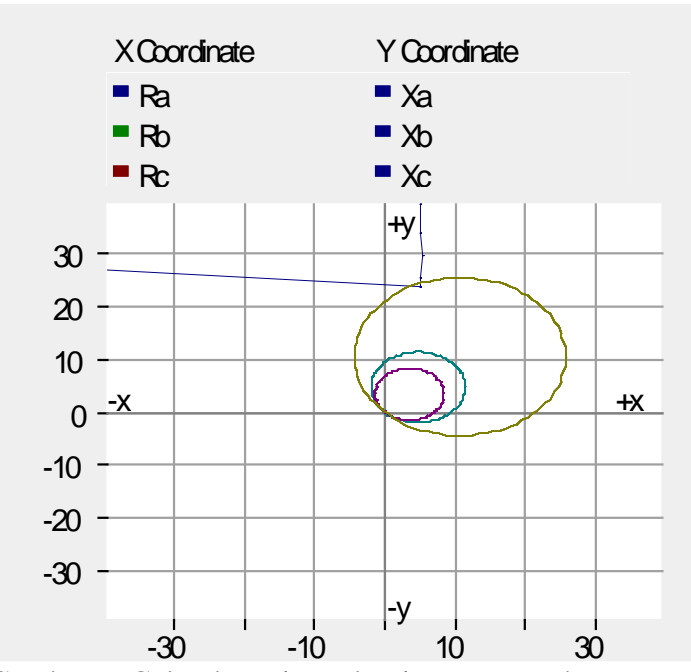

Gambar 7. Gelombang impedansi gangguan phasa-netral Zona 3

Berdasarkan hasil simulasi dengan menggunakan PSCAD didapatkan hasil bahwa semua gelombang impedansi gangguan berada dalam lingkaran kurva mho sehingga saat terjadi gangguan maka rele jarak dapat dipastikan bekerja sesuai setting yang telah dihitung.

\section{KESIMPULAN DAN SARAN}

\subsection{Kesimpulan}

1. Hasil perhitungan impedansi urutan positif untuk penghantar 3 phasa dengan konduktor ACSR $2 \times 240 \mathrm{~mm}$ dengan 2 berkas konduktor tiap phasa adalah $0,0669+j 0,18710 \mathrm{hm} / \mathrm{km}$.

2. Impedansi urutan positif SUTT $150 \mathrm{kV}$ Garuda Sakti - Pasir Putih sebesar 2,0857+ j5,8307 Ohm $/ \mathrm{km}$.

3. Hasil perhitungan impedansi urutan nol adalah $0,4005+j 1,37180 \mathrm{hm} / \mathrm{km}$ dan impedansi gandeng urutan nol adalah 0,3335+ 1,3525 $\mathrm{Ohm} / \mathrm{km}$,

4. Impedansi urutan nol didapatkan kompensasi urutan nol SUTT 150kV Garuda Sakti - Pasir $\operatorname{Putih}\left(K_{0}\right)$ sebesar 2,0644 $\angle 3,9582^{\circ}$.

5. Setting rele jarak untuk saluran transmisi Garuda Sakti arah Pasir Putih Zona-1 sebesar $1,0529 \angle 80,2778^{\circ}$ Ohm dengan waktu kerja seketika (0 detik), Zona-2 2,2519 $\angle 81,1040^{\circ} \mathrm{Ohm}$ waktu kerja 0,4 detik dan Zona-3 3,3778 $\angle 81,1040^{\circ}$ Ohm waktu kerja 1,2 detik.

\subsection{Saran}

Berdasarkan hasil perhitungan didapatkan bahwa nilai impedansi suatu saluran transmisi bergantung pada material konduktor dan jarak geometri pemasangan antar konduktor. Dalam setting rele jarak disarankan agar PT. PLN (Persero) UPT Pekanbaru dapat menggunakan hasil perhitungan ini. Apabila terjadi perubahan konfigurasi jaringan seperti uprating/penggantian konduktor atau transformator daya, maka setting rele jarak harus disesuaikan/dirubah.

\section{DAFTAR PUSTAKA}

[1] Hutauruk, T. S., Transmisi Daya Listrik. ISBN 3503-0055, Erlangga, Jakarta, 1996.

[2] Anderson, P. M., Analysis of Faulted Power Systems, ISBN 0-7803-1145-0, Wiley Interscience, Iowa, 1995.

[3] Saadat, H., System Analysis, New York, The McGraw-Hill Companies Inc, 1999.

[4] Carpenter,W. Mark, IEEE Guide for Protective Relay Applications to Transmission Lines, ISBN 0-7381-1831-1, The Institute of Electrical and Electronics Engineers, Inc., New York, 1999.

[5] Coock, V., Analysis Of Distance Protection, ISBN 0-86380-027-0, Research Studies Press Ltd., Wales, 1985.

[6] PT. PLN (Persero), Relai Jarak Sebagai Pengaman Utama Pada Pola Proteksi SUTT, Udiklat Semarang, Semarang, 2006. 